\title{
Gender Study on Knowledge and Decision Making on Maternal Health Care in Nepal
}

\author{
Shrestha $\mathbf{B}^{1}$ \\ ${ }^{1}$ Department of Community Medicine and Public Health, \\ Maharujgunj Medical Campus, Institute of Medicine, TU, Nepal
}

\begin{abstract}
Background: The enjoyment of the highest attainable standard of health is one of the fundamental rights of every human being, without distinction of race, religion, and political belief, economic or social condition.(1). There still exist differences in the factors determining health and the burden of ill-health for women and men. The study is based on addressing the maternal health problems with gender perspectives, and the factors associated with health seeking practices. The main objectives of the study are to find out maternal health problem and gender analysis on decision making (household matters and health care) and the knowledge on danger signs in mother and newborn.
\end{abstract}

Methods:The study is descriptive and cross sectional in design. Household surveys were conducted by the study team in 24 sample VDCs of Baglung, Dolakha and Ramechhap.

Results: A total of 959 women were interviewed and 112 (11.40 percent) of them reported having faced emergency obstetric problems and about 5.6 percent of the respondents were found to be suffering from Uterus prolapse problems. The men were found getting more $(81.2$ percent) opportunities for education than women (58 percent). Women were found to be limited more to household activities that have low economic/monetary value (Women vs. Men: 41.83 percent Vs 4.49 percent) in comparison to men. The women's status was found to be lower than that of men in all the indicators. The types of occupation were also clearly distinct between men and women in the study districts. Women had better knowledge (50 percent Vs 25 percent) on danger sign in mother and newborn but did not get opportunity of making decision to access health care in time. They were found having to follow their husband's or in-laws's decision.

Conclusion: Appropriate initiative should be taken for women empowerment in order to develop women autonomy for maternal health care.

Key words: Gender, Maternal Health, Neonatal health, Emergency Obstetric care, danger signs, decision making, gender status, equity and equality

\section{Background}

"The enjoyment of the highest attainable standard of health is one of the fundamental rights of every human being without distinction of race, religion, and political belief, economic or social condition" (1). Gender is used only to describe those characteristics of women and men, which are socially constructed, while sex refers to those which are biologically determined. Gender analysis in health often highlights how inequalities affect women's health, the constraints women face to attain health and ways to overcome these inequalities. Gender analysis also reveals health risks and problems which men face as a result of the social construction of their roles.

There are differences in the opportunities and resources available to women and men, and in their opportunity in making decision and in exercising their human rights, including those related to protecting health and seeking care in case of ill health. Gender roles and unequal gender relations interact with other social and economic variables, resulting in different and sometimes inequitable patterns of exposure to health risks, and in differential access to and utilization of health information, care and services. These differences, in turn have clear impact on health outcomes. Evidence documenting the multiple connections between gender and health is rapidly growing. (2)

Gender issues play an extremely significant role in the lives of Nepalese women and their dependent children. Broadly speaking, Nepalese society assigns tightly defined gender roles to men and women. These stereotypical roles are at the root of prejudiced attitudes that feed into discriminatory practices throughout the society. These practices, along with the attitudes that accompany them have a foundation in the family settings, and are reflected in the administrative and legal practices of the country. Together, they create a cycle of discrimination that puts women in an inferior position to men and perpetuates their lower status. Women in Nepal find themselves in a vicious circle that drives the discrimination against their gender. Their generally low status means that most women are not given sufficient

CORRESPONDENCE: Assistant Professor Binjwala Shrestha (Public Health Sociologist), Department of Community Medicine and Public Health, Maharujgunj Medical Campus, Institute of Medicine, TU, Kathmandu, Nepal. Mobile: 9851053747 Email: binjwala_shrestha@hotmail.com Supporting organizations: Mobility and Health Research Project, International Forum for Rural Transport, Development /District Road Support Program (IFRTD/DRSP) and Swiss Development Cooperation/ Rural Health Development Project (SDC/RHDP). 
decision- making power to control their own access to resources, such as information, services, money, etc. This restricted access to resources prevents women from developing their decision-making capacity. (3)

Nepal is signatory to almost all international conventions on human rights, women's rights, and children's rights as well as to agreements on international goals regarding education, health, and poverty eradication. The International Conference on Population and Development (ICPD) and ICPD+10 commit Nepal to ensuring women's universal access to reproductive health as well as equal access to all other health services. The Millennium Development Goals (MDGs) commit Nepal to achieving minimum educational, health, and poverty reduction targets and making sure that women and girls share benefits equally as these goals are achieved. (4)

Gender inequality causes and perpetuates poverty and vulnerability. But greater gender equality can help to reduce the root causes of poverty and vulnerability and contribute to sustainable pro-poor growth. Given that the Millennium Development Goals (MDGs) address key development challenges, one would expect a gender focus throughout the goals. The fact is that experiences of poverty differ according to sex, age, ethnicity and location. (5)

\section{Model}

The study model is based on addressing the maternal health problem and its factors associated with health seeking practices with gender perspectives. The inequality in gender power relations operate across a wide spectrum of human life and in inter-related ways. Taking such actions is good for the health of all people - girls and boys, women and men. In particular, inter-sectoral actions to address gender inequality are critical to the realization of the Millennium Development Goals (MDGs). The gender inequality and equity in health are socially governed and therefore actionable. Sex and society interact to determine who is well or ill, who is treated or not, who is exposed or vulnerable to ill-health and how, whose behavior is risk prone or risk-averse, and whose health needs are acknowledged or dismissed. The gender study involves: looking at sex/gender sexdisaggregated data, trying to interpret the meaning of the differences (gender analysis), and taking the differences into account in planning research or programme interventions (gender-sensitivity). (6)

\section{Rationale}

Gender significantly influences a person's ability to access health services. The power relations between women and men influence awareness of such conditions and the adoption of appropriate responses can help women and men to improve their health and advance in life, and can enrich the quality of life in their communities. The roles that women and men play should guide the ways in which clinic staff assess their clients' needs and provide care. (7)
A recent research based on data from the 2001 census shows that women's access to share in percentage literacy, education, and decision-making roles, amongst other indicators, is below that of men, regardless of caste or ethnicity. The table 1 shows clear gender inequality in Nepal.

Taking action to improve gender equity in health and to address women's rights to health is one of the most direct and potent ways to reduce health inequities overall and ensure effective use of health resources. (8)

The analysis of NDHS 2006 on women's health seeking behavior revealed that there are several female specific barriers in accessing health care services from the health facilities. They are unwilling to go alone, and female care providers are not available. Distance was reported as access barrier by more than 60 percent of women. In addition, decisions on their own health care were mainly taken by husband or someone else (presumably other family members for unmarried women) in more than half of the cases and problems in getting money for treatment was reported by 39 percent of all women and 50 percent of poor women. Further, there are gender biases in health-care seeking behavior for children; boys are more likely than girls to be taken to health care providers when suffering from fever, and more likely to receive antibiotics for ARI, though these differences are not reflected in mortality outcomes.

In this context, this study is focused mainly on exploring the gender issues and factors associated with access to maternal health care at rural community of study districts. This paper is concentrated on studying the gender differences in opportunity for education, decision making (household matters and health care) and awareness on danger signs during pregnancy, delivery, post delivery and newborn in order to find out the access to maternal health care to identify the role of gender in each components of study.

Objectives: The objectives of the study are to describe the gender status in opportunity for education, employment, decision making (household matters and health care); to find out the status of maternal morbidity (self reported) in selected districts and to find out about decision making on maternal care and awareness of danger signs viz. maternal health problems during pregnancy, delivery, postnatal and in new born.

\section{Methodology}

Study site: The study is descriptive and cross sectional in design. Three hilly districts, namely Dolakha, Ramechhap and Baglung were the study sites. The study was conducted from November 2006 to February 2007 and a total of 24 Village Development Committees (VDCs) were selected for this purpose. These districts are mostly hilly and mountainous ones, where access has historically been very limited and the communities have had difficulties to access the health services. The districts have relatively high mortality rates, which contribute to an overall high rate for the country. (9) 
The districts have a significant proportion of poor communities; most people are from disadvantaged communities and the level of womens empowerment is still poor. Although a transformation process has already started in these districts, these have not yet been completed, and, therefore, offer added opportunities for maternal health improvement in the near future. The districts were well known to the research team, all had poor and disadvantaged groups within the community, equipped with the required level of road access enabling access to more detailed and accurate information from households. They were also in access to nearby referral hospitals with the emergency obstetric care services.

\section{Sampling and Study population}

Stratified quota sampling technique was used to ensure the equal representation from Brahmin/Chhetri/Newar, Janajati and Dalit. Around 1,200 households were interviewed in each of the three districts, that is 50 households times 24 VDCs. The respondents are more or less equally distributed from three study districts; Dolakha $(\mathrm{N}=373)$, Ramechhap $(\mathrm{N}=392)$ and Baglung $(\mathrm{N}=387)$. The composition of the study population by caste/ethnicity is also equal Brahmin/Chhetri/ Newar (N=364), (Janajati N=383), and Dalit (N=392).

\section{Data collection}

Household survey was carried out using structured questionnaire on demographic and socioeconomic data and gender related information in the study districts. A total of 959 women (mother with 0-2 year child) and 755 men (father with 0-2 year child) were interviewed to collect socioeconomic background, knowledge, attitude and practices (KAP) on maternal health care in the study districts.

\section{Data Processing and Analysis}

Quantitative data were coded and analyzed using MS excel and SPSS software. Tables were produced after validating the data. The study variables were family background, socioeconomic status, gender analysis on decision making for household expenses and health care seeking, women's knowledge on danger signs of antenatal, delivery, post natal and neonatal period.

Disaggregation was done according to gender, to analyze gender difference in socioeconomic profile, workload, decision making and KAP on maternal health care.

Limitations of the study: The study is based on the outcomes of research works in three selected districts and can be used only for hill and mountainous districts. The informants of the study are mainly mothers, fathers and families having children aged 0 to 2 years. The data includes figures provided by informants and therefore will give information based on the respondent's memory.

\section{Results}

\section{Socio-economic background of respondents}

The overall socioeconomic condition is low in Ramechhap. The analysis shows that dalits are the poorest, and only 10.35 percent of them have sufficient income, whereas it is 37.2 percent for the BCNs and 24.4 percent for Janjatis. Similarly, the literacy rate of dalits is only 46.8 percent in comparison to the BCN (71.8 percent) and Janajatis (57.9 percent).

The composition of study population is almost similar to the national average. The average family size of the sampled household was 6.26 and the sex ratio 0.89 ( 89 males per 100 females). The distribution of total respondents and their demographic and socio-economic background is given in table 1 .

Table 1: Demographic and socio-economic characteristics of the respondents

\begin{tabular}{l|l|l|l|l|l|l}
\hline \multirow{2}{*}{ Indicators } & \multicolumn{3}{|c|}{ District } & \multicolumn{3}{c}{ Caste / Ethnicity } \\
\cline { 2 - 7 } & Dolakha & Ramechhap & Baglung & BCN & Janajati & Dalit \\
\hline $\begin{array}{l}\text { Number of } \\
\text { respondents }\end{array}$ & 373 & 392 & 387 & 364 & 383 & 392 \\
\hline $\begin{array}{l}\text { Sufficiency of } \\
\text { income percent }\end{array}$ & 21.9 & 17.6 & 30.4 & 37.2 & 24.4 & 10.3 \\
\hline \begin{tabular}{l} 
Literacy percent \\
\hline $\begin{array}{l}\text { Families with } \\
\text { migrants percent }\end{array}$
\end{tabular} & 56.3 & 43.8 & 73.0 & 71.8 & 57.9 & 46.8 \\
\hline
\end{tabular}

Source: Household survey in Baglung, Ramechhap and Dolakha 2006

\section{Situation of Emergency Obstetric Problem}

The situation of emergency obstetric problems faced by women is based on the responses collected from the mothers of the (0-2 year) child in three study districts. Out of total 959 respondents, 112(11.40 percent) had faced emergency obstetric problems. The distribution of types of the emergency obstetric problems is given in table 2 .

Table 2: Distribution of the emergency obstetric problems faced by women

\begin{tabular}{l|c}
\hline Emergency problems (N 112) & Percentage \\
\hline Post delivery bleeding & 17.43 \\
\hline Retained placenta with post-delivery bleeding & 20.18 \\
\hline Obstetric labor due to abnormal lie & 20.18 \\
\hline Convulsion & 20.18 \\
\hline Others & 36.89 \\
\hline
\end{tabular}

Source: Household survey in Baglung, Ramechhap and Dolakha 2006

\section{Situation of uterine prolapse problem:}

About 5.6 percent of the respondents were found to be suffering from (self reported and diagnosed) Uterine prolapse which indicates that it is prevailing in 54.00 out of 959 
households in three study districts.

4. Gender analysis on opportunities for education, awareness on danger signs, employment and decision making

\subsection{Education Opportunities}

The study revealed that women in the study districts were found to be getting less (literacy in women 58 percent and 81.2 percent in men) opportunity for education in comparison to men. Table 3.

\begin{tabular}{l|c|c}
\hline Educational status & $\begin{array}{c}\text { Women percent } \\
(\mathrm{N}=959)\end{array}$ & $\begin{array}{c}\text { Men percent } \\
(\mathrm{N}=755)\end{array}$ \\
\hline Illiterate & 42.0 & 18.8 \\
\hline Literate & 58 & 81.2 \\
\hline
\end{tabular}

Table 3: Educational status of the respondents in study districts

Source: Household survey in Baglung, Ramechhap and Dolakha 2006

\subsection{Awareness on danger signs of maternal and new born health among men and women}

The results showed that more women (women; 50 percent and men; 25 percent) were aware about the dangers signs during pregnancy. In the same way men were found less aware ( 36.45 percent) on the importance of post natal care. However, both men and women were found more or less equally aware about the dangers signs during post natal period, new born care and health facility providing emergency obstetric and new born care. Table 4 .

\begin{tabular}{|c|c|c|}
\hline $\begin{array}{c}\text { Awareness on maternal and } \\
\text { new born }\end{array}$ & $\begin{array}{l}\text { Women percent } \\
(\mathrm{N}=959)\end{array}$ & $\begin{array}{c}\text { Men percent } \\
(\mathrm{N}=755)\end{array}$ \\
\hline $\begin{array}{l}\text { Knowledge on danger signs } \\
\text { during pregnancy }\end{array}$ & 49.13 & 24.78 \\
\hline $\begin{array}{l}\text { Knowledge on danger signs of } \\
\text { delivery and post natal period }\end{array}$ & 82.54 & 70.50 \\
\hline $\begin{array}{l}\text { Knowledge on danger signs of a new } \\
\text { born baby (within } 24 \text { hours) }\end{array}$ & 74.7 & 87.88 \\
\hline Knowledge on importance of PNC & 58.98 & 36.45 \\
\hline $\begin{array}{l}\text { Knowledge on health facilities } \\
\text { for EmOC }\end{array}$ & 90.68 & 95.28 \\
\hline $\begin{array}{l}\text { Know on health facilities for } \\
\text { new born care }\end{array}$ & 16.00 & 15.00 \\
\hline
\end{tabular}

Source: Household survey in Baglung, Ramechhap and Dolakha 2006

Table 4: Distribution of awareness on maternal and new born care among women and men

\subsection{Employment opportunity and work load}

The types of occupation by gender were clearly distinct in the study districts. Women were found to be limited more to household activities that have low economic/monetary value (Women vs. Men: 41.83 percent and 4.49 percent) in comparison to men. But as regards to the monetary- income- based occupations i.e. business, service and daily wages, it was the opposite; (Women vs. men: 5.5 percent and 33.74

\begin{tabular}{l|c|c}
\hline \multicolumn{1}{c|}{ Type of occupation } & $\begin{array}{c}\text { Women percent } \\
(\mathbf{N}=959)\end{array}$ & $\begin{array}{c}\text { Men percent } \\
(\mathbf{N = 7 5 5 )}\end{array}$ \\
\hline Household chores (Self employed) & 41.83 & 4.49 \\
\hline Farming (Self employed) & 52.66 & 61.73 \\
\hline Business/Services/Daily wages labor & 5.5 & 33.74 \\
\hline
\end{tabular}

Source: Household survey in Baglung, Ramechhap and Dolakha 2006

percent).Table 5

Table 5: Distribution of occupation of men and women in study districts

The average working hours of men and women also show a clear disparity. On the average, the average working hours of women was 13 in comparison to 8 of men. This indicates that more women are dependent on the family and their husbands as they are mostly involved in care economy.

The distribution of household responsibilities between men and women were almost of the same pattern in all the three districts: Men believed that childcare and household chores were not for them. Men tended to control the household resources in all study districts, recreation and community meetings were extra activities of men, but are not undertaken at all by women. The sharing of household activities was not practiced and there was little opportunity for women to participate in recreational activities. This is likely to impact the decision making for health care as well.

\subsection{Decision making for household expenses}

The delay in decision making in accessing health care for ANC, delivery, emergency obstetric care and post natal period was gender-biased and a major factor for higher maternal morbidity and mortality in remote rural areas. These delays in decision-making is attributed to various factors such as lack of ownership in property, low social status etc. In the household survey, it was found that the property (land, house) ownership among women was only 0.85 percent, which might be the reason behind women's low bargaining power to access

\begin{tabular}{c|c|c}
\hline Decision Makers & $\begin{array}{c}\text { Women's response } \\
\text { percent }(\mathrm{N}=959)\end{array}$ & $\begin{array}{c}\text { Men's response } \\
\text { percent }(\mathrm{N}=755)\end{array}$ \\
\hline Men & 54.5 & 74.1 \\
\hline Women & 34.8 & 17.7 \\
\hline Both & 10.7 & 8.2 \\
\hline
\end{tabular}

health services. Table 6

Table 6: Family decision making system for household expenses

Source: Household survey in Baglung, Ramechhap and Dolakha 2006

The responses of men and women interviewed also varied with regard to decision making power. It was found that 35 percent of the women responded that they were making decision in the family themselves. Chances are that these women have power of decision-making, not because of their status but because the male family members were absent in 
the family due to seasonal migration. But where the male head of household was nresent they tended to control the

\begin{tabular}{l|c|c} 
Decision Makers & $\begin{array}{c}\text { Women's response } \\
\text { percent (N=959) }\end{array}$ & $\begin{array}{l}\text { Men's response } \\
\text { percent (N=755) }\end{array}$ \\
\hline Men & 4.1 & 37.2 \\
\hline Women & 39.0 & 59.4 \\
\hline Jointly, by all family members & 23.8 & 36.5 \\
\hline
\end{tabular}

Source: Household survey in Baglung, Ramechhap and Dolakha 2006

resources, showing that only men made decisions in 74 percent of the families. Table 7

Table 7: Decision making at family for women's health care

\section{Discussion}

Access to emergency obstetric care and maternal health situation

The met need (the proportion of expected obstetric complications treated in EMOC facilities) is based on the evidence that at least 15 percent (Hibbard, 1978; Hartfield, 1980) of all pregnant women develop sudden serious complications and require access to life saving quality obstetric services or procedures. (10)

The met need of Nepal is only 24.8 percent (target is 100 percent) as reported in 19 districts. (11). In this study about 11 percent of women had family faced various types of emergency obstetric problems. The 33 maternal mortality cases in 24 VDCs in three study districts in three years revealed high incidence of maternal death (9). Maternal mortality ratio, which stands at 281/100,000 live births is one of the highest in the world and the fertility rate of 3.1 is also very high compared to other parts of the world. The prevalence of uterine prolapse is 7 percent in women between the age of 15-49. (12)

All these findings indicate that women in hill and mountainous districts are facing problems of emergency during child birth, developing uterine prolapse due to lack of quality delivery care services. As a result, some of them are dying due to inordinate delay in seeking timely health care. The factors associated with access have been analyzed in the article (9).

\section{Gender development and women empowerment}

Gender-based discrimination is rampant in Nepali society. It affects all women, regardless of their economic status, caste, ethnicity, or regional affiliation. A patriarchal worldview is embedded not only in social and cultural practices, but also in Nepal's systems of governance and its legal framework, permeating all aspects of the lives of women and girls. (13).

"Gender-related Development Index" (GDI) and "Gender Empowerment Measure" (GEM) are the main indicators to present the status of women development in the country. The GDI value as 0.499 and the GEM value as 0.496 reveal the existing gender inequality in Nepal. The discrepancies in the GDI and GEM values point to a persisting exclusion of women in decision-making and control over resources. Heritage lies at its root-the historic exclusion imposed by patriarchal society and exclusionary state policies. (13)

Gender relations of power constitute the root causes of gender inequality and are among the most influential of the social determinants of health. They determine whether people's health needs are acknowledged, whether they have a voice or a modicum of control over their lives and health and whether they can realize their rights. This study is focused to identify the status of gender in socioeconomic condition of the study population.

\section{Gender inequality and maternal health}

The study shows that more men (81.2 percent) are getting opportunity for education in comparison to women (58 percent). However the awareness level on danger signs of mothers' and new borns health problems were more or less equal among men and women. Regarding danger signs of pregnancy period, only 25 percent of men had such knowledge where as 50 percent of women were found to have knowledge on these problems. Table 4

If this finding is linked with the opportunity to make decision for health care and family expenses, it becomes clear that it is mostly the men, not women who are making such important decisions. It is also quite clear that the status of women in the family is defined mainly by their bargaining positions, or power and that is directly linked with the employment status of women. The types of occupation by gender are clearly distinct in the study districts. Women were found to be limited more to household activities that have low economic/monetary value. Table 5

Similarly, women's little access to decision-making opportunities is attributed to various factors like no ownership in property, low social status etc. In the household survey, it was also found that the property (land, house) ownership among women was only 0.85 percent. It might be the reason behind women's low bargaining power to access health services.

Further, when decision making patterns with regard to women's and men's health care were analyzed it was found that most decisions on men's health care were made by men themselves. However, 39 percent of women's health care decisions were made by men and women were making only 37.2 percent of the decisions by themselves. Table 6 and 7

Such an unbalanced situation can obviously have negative impacts on making prompt and appropriate decisions, especially in emergency situations. On the basis of the 
findings above, one can safely say that the present health care system is clearly and heavily biased towards men in Nepali society, which means that women's health will continue to suffer disproportionately as a result.

\section{Conclusions}

Most women do not have decision making opportunity for maternal health care

Women have less autonomy for health care. Men make most of their health care related decisions by themselves, however only 37.2 percent of women get opportunity to make decision for their health care. Women are found to be limited more to household activities that have low economic/monetary value. More women are dependent on the family and their husband, as they are mostly involved in care economy.

\section{Magnitude of maternal morbidity}

The women of three study districts revealed that 11.40 percent had faced emergency obstetric problems and 5.6 percent of the women were found to be suffering from uterus prolapse (self reported).

\section{Gender differences in awareness on danger signs of maternal health}

Women have better knowledge on danger sign of a mother's and newborn's health, but they do not get enough opportunity to make decision making power to access health care in time. They have to follow their husband's or in-laws decisions, as very few women can make decisions by themselves for their health care.

\section{Recommendation}

The education of girl child, women empowerment, health education on maternal health right, mens participation in ANC and delivery care would be he initiatives to develop women autonomy for maternal health care in order to reduce the delay in decision making.

\section{Acknowledgements}

I express our thanks and appreciation to Mr. Robin Workman for coordinating the research program and also for managing all the logistic supports from the Mobility and Health Research Project, International Forum for Rural Transport Development/District Road Support Program (IFRTD/DRSP

\section{References}

1. Universal Declaration of Human Right (UDHR) 1945 article 25

2. WHO Gender Policy: Integrating Gender Perspectives in the Work of WHO 2002; page 3 and 6

3. UNICEF, Situation of women and girl in Nepal, 2006: page 61
4. Gender Equality and Empowerment of Women in Nepal 2007; page 17

5. All participants of the WWPWFM, Hamilton/McMaster meeting, August 2006, 21-24

6. Jane Cottinggham, Department of Health and Research, September 1999 www.gfmer.ch/Endo/Lectures_09/Pdf/ Gender_perspectives

7. http://erc.msh.org/TheManager/English/V9_N2_En_Issue Managing Reproductive Health Services with a Gender Perspective: The ERC is produced by Management Sciences for Health, p 9

8. "Unequal, Unfair, Ineffective and Inefficient Gender Inequity in Health: Why it exists and how we can change it", Final Report to the WHO Commission on Social Determinants of Health September 2007 Women and Gender Equity Knowledge Network, by Gita Sen and Piroska Östlin et all; p 9

9. Binjwala Shrestha, Institute of Medicine, Maternal Mortality in hilly districts of Nepal, Journal of Institute of Medicine, August, $2009 ; 31: 2$

10. AMDD Workbook, Using the UN Process Indicators of Emergency Obstetric Services, February 2002, p 5

11. Department of Health Services (DoHS/HMIS) 2008/2009 , Annual Report p 118

12. Nepal Demographic and Health Survey 2006, Population Division, Ministry of Health and Population, Government of Nepal. New ERA, Kathmandu, Nepal Macro, International Inc., Calverton, Maryland, U.S.A, 2007;5:p 133 and 146

13. Nepal Human Development Report 2009 p: 18, 39 and 40 